\title{
ESPORTES NÁUTICOS, IDENTIDADES CULTURAIS E O POSITIVIS- MO NO RIO GRANDE DO SUL
}

\author{
Carolina Fernandes da Silva \\ Universidade Federal de Viçosa, Viçosa, Minas Gerais, Brasil \\ Janice Zarpellon Mazo \\ Universidade Federal do Rio Grande do Sul, Porto Alegre, Rio Grande do Sul, Brasil \\ Mayara da Silva Miranda Araujo Carneiro \\ Universidade Federal de Viçosa, Viçosa, Minas Gerais, Brasil
}

\begin{abstract}
Resumo
O presente estudo busca investigar como os clubes esportivos náuticos assimilaram representações sul-rio-grandenses no início do século XX. Os clubes esportivos náuticos no Rio Grande do Sul (RS) foram implantados por imigrantes europeus. A partir do contato cultural que ocorreu entre os imigrantes, novas identidades foram compostas. Neste contexto se constituíram as identidades sul-rio-grandenses dos clubes, com novas representações no cenário esportivo. O corpus documental foi constituído de fontes impressas, extraídas de documentos oficiais dos clubes e jornais que circulavam pelo estado. A análise das fontes ocorreu através do software ATLAS.ti 7.5.6. Por meio da interpretação do cenário dos clubes náuticos no RS, é possível perceber que o estado era heterogêneo culturalmente.
\end{abstract}

Palavras-chave: História do Esporte. Remo. Clubes. Identidades.

\section{Introdução}

Os clubes esportivos náuticos no Rio Grande do Sul foram implantados, na sua grande maioria, por imigrantes europeus que chegaram ao estado, entre fins do século XIX e início do século XX. Ao longo do período de estabelecimento, a partir de contatos culturais entre estes imigrantes, novas identidades foram compostas e recompostas. Tais negociações identitárias repercutiram no contexto clubístico, como também foram produzidas por estes clubes (SILVA, 2015).

O esporte, vislumbrado enquanto prática cultural, em cada país adquire diversos significados que, paulatinamente, se conectam por meio de artefatos e regras globais. O Brasil, com uma extensão territorial de 8.515.767.049 km² (IBGE, 2016), com 26 estados e mais o Distrito Federal, conta com uma grande diversidade cultural e diferentes identidades regionais, construídas historicamente. As regiões do país se formaram de maneira diversa, por nativos e imigrantes, que chegaram pelas fronteiras ou pelos portos. Os imigrantes foram os principais sujeitos da globalização esportiva, especialmente no caso do estado do Rio Grande Sul. 
O sentido de imigração é sustentado na ideia de diferença, a qual, de acordo com Hall (2003), resulta da "natureza intrinsecamente hibridizada de toda identidade e das identidades diaspóricas em especial" (p. 15). Para Canclini (2011), os contatos culturais trazem a ruptura da ideia de pureza, pois é uma prática multicultural, possibilitada pelo encontro de diferentes culturas. Contatos culturais podem ser observados em cidades do estado do Rio Grande do Sul.

Porto Alegre, durante o século XIX, já era a capital do estado, mas as conexões de Rio Grande e Pelotas com cidades da Argentina e do Uruguai contribuíam para fortalecer o poder econômico da região sul do Rio Grande do Sul. A exportação e a importação de mercadorias ocorriam, principalmente, pelos portos de Buenos Aires e Montevidéu, os quais são mais próximos geograficamente de Pelotas e Rio Grande. Além disso, o transporte de mercadorias no Uruguai e na Argentina, dinamizado pelas ferrovias, provocou a desterritorialização de mercadorias e culturas (CANCLINI, 2001). Tais circunstâncias agitavam os portos das três cidades sul-rio-grandenses referidas acima e proporcionavam trocas culturais, expressão utilizada por Burke (2003).

Os acontecimentos no cenário econômico e sociocultural ecoavam no campo do associativismo esportivo. Até o princípio do século XX, no Rio Grande do Sul havia 62 clubes esportivos situados nas cidades de Pelotas, Porto Alegre e Rio Grande, sendo oito clubes dedicados à prática dos esportes náuticos (MAZO et al, 2012). O primeiro clube de remo do estado foi fundado por imigrantes alemães e seus descendentes (SILVA, 2011). Os idealizadores do Ruder Club Porto Alegre conheceram e praticaram o remo no período em que estudaram na Alemanha. A partir deste, surgiram novos clubes com diferentes identidades culturais (SILVA, 2015).

A fundação do Club Náutico Rio-Grandense, em Porto Alegre, no ano de 1907, foi um dos primeiros indícios dessa movimentação para regionalizar os clubes de remo e natação, não apenas no caráter espacial, mas, inclusive, na esfera das representações culturais, o que vem a consolidar-se com a modificação do Comitê de Regatas para a instauração da Federação Rio-Grandense de Remo (FRGR). Possivelmente, isso aconteceu em reação às diversas modificações no cenário do esporte náutico nacional. De tal modo percebem-se indícios de que os esportes náuticos no Rio Grande do Sul estavam envolvidos por diversas representações, as quais foram recompostas ao longo dos anos, se modificando de acordo com o contexto cultural.

Diante de tal cenário, surge a seguinte questão norteadora do estudo: como os clubes esportivos náuticos assimilaram representações culturais sul-rio-grandenses no início do século XX? O historiador Peter Burke (2003) afirma que os pesquisadores em história, cada vez mais, dedicam-se à análise dos processos de encontro, interação, troca e contato cultural. Nesta perspectiva, justifica-se este estudo, pois se considera necessário que os pesquisadores em História do Esporte busquem analisar os processos de trocas e contatos culturais por meio das práticas esportivas, bem como do fenômeno do associativismo esportivo. Sebastien Darbon (2008) afirma que houve um crescimento de pesquisas históricas voltadas para o esporte sob a luz da globalização. No caso dos estudos históricos no Brasil, ainda há lacunas sobre como as culturas se conectam por meio dos esportes, como no caso do remo.

Para a realização deste estudo, foram utilizadas fontes impressas para constituir o corpus documental. As informações foram extraídas principalmente de documentos oficiais dos clubes, como estatutos, e jornais que circulavam pelo estado, no período demarcado pela pesquisa. A análise das fontes ocorreu com o auxílio do software de análise qualitativa dos dados ATLAS.ti 7.5.6. O presente software é uma ferramenta propícia à análise dos dados e permite ao pesquisador a escolha dos objetivos, dos instrumentos e das categorias de análise, dando credibilidade e confiabilidade a sua investigação (GILZ, 2007). Este possibilita, dentre várias vantagens, "a estruturação lógica e coerente de uma pesquisa nas suas diversas etapas: fun- 
damentação teórica, coleta de dados, análise e apresentação dos resultados" (GILZ, 2007, p. 4016). mações.

Nos tópicos que seguem, apresentam-se os resultados da análise qualitativa das infor-

\section{Representações culturais sul-rio-grandenses: a elaboração de identidades}

A localização do Rio Grande do Sul, uma área limítrofe, possibilitou que este estado fosse visto como parte tanto do Brasil quanto de outros países, dependendo das forças históricas em jogo (OLIVEN, 1997). Outra evidência, que corrobora essa afirmação, é a de que "a linguagem dos gaúchos é recheada de expressões espanholas e seus costumes estão muito próximos de seus vizinhos argentinos e uruguaios" (MARRERO, 2006, p. 14).

Segundo o escritor Vitor Ramil (2009), em sua apresentação A estética do frio no Théâtre Saint-Gervais, em Genebra, Suíça, no dia 19 de junho de 2003, como parte da programação Porto Alegre, un autre Brésil - mais tarde, transformada em livro -, em um país tão grande como o Brasil é difícil que as regiões se conheçam bem, por isso se utilizam de estereótipos e fixam imagens imprecisas umas das outras. O termo gaúcho "é, hoje em dia, um gentílico que designa os habitantes do Rio Grande do Sul, e o estereótipo do gaúcho é um dos mais difundidos nacionalmente, se não o mais difundido: misto de homem do campo e herói" (RAMIL, 2009, p. 11).

De acordo com Petri (2008), essa alcunha advém da região do pampa (uruguaio e argentino), avançou para além das fronteiras do Rio Grande do Sul e chegou ao restante do Brasil, que passou a reconhecer essa designação como sinônimo de pessoas nascidas no Rio Grande do Sul, os rio-grandenses-do-sul ou sul-rio-grandenses. Vitor Ramil (2009) complementa que o gaúcho é um tipo comum aos vizinhos Uruguai e Argentina, com a diferença de que, nesses países, gaucho - palavra em espanhol - é meramente o homem do campo. "É significativo que, no variado leque de tipos regionais brasileiros, esse mesmo gaúcho tenha se estabelecido como marca de representação de todos os rio-grandenses, justamente ele, que nos vincula aos países vizinhos, que nos 'estrangeiriza"” (RAMIL, 2009, p. 12).

Para Marrero (2006, p. 14), "de modo geral, os gaúchos e gauchos são reconhecidos como um grupo de homens marcados por uma visível unidade cultural". Isto ocorre devido a sua origem étnica cultural, que é, basicamente, a mesma e reporta para uma herança ibérica, indígena e africana. Esta está associada "a atividades pastoris nas planícies do Pampa sulamericano, uma área geográfica extensa que sobrepõe os limites de fronteiras dos países da região (Brasil, Argentina e Uruguai)" (MARRERO, 2006, p. 14).

Verli Petri (2008) acrescenta ainda que o termo gaúcho carrega as relações sociais que lhe são atribuídas como constitutivas, uma vez que se vincula como "um integrante do grupo social constituído pela miscigenação racial própria do sul do Brasil (negros, índios, descendentes de europeus) e vinculado, atualmente, às lutas sociais pelos direitos à terra e à dignidade" (p. 231). Esta configuração estava e permanece viva principalmente no imaginário interiorano, onde a pecuária e a agricultura foram as fontes econômicas e o trabalhador rural era a principal profissão. Quando da construção da identidade sul-rio-grandense, em um "processo de glorificação do gaúcho, que faz parte da construção social de sua identidade, torna-se necessário distingui-lo do gaúcho de outros países" (OLIVEN, 1989, on-line) e lembrar que, antes de ser gaúcho, era parte do Brasil.

A formação da cultura sul-rio-grandense também foi constituída de representações europeias, dentre estas estavam inclusive tendências filosóficas, como o positivismo ${ }^{1}$. A doutri-

\footnotetext{
${ }^{1} \mathrm{O}$ positivismo é uma corrente filosófica científica, que despontou buscando a resolução dos graves problemas sociais europeus, principalmente franceses.
} 
na positivista foi disseminada pelo Brasil no fim do século XIX. No Rio Grande do Sul, ela foi introduzida, assimilada, aceita e praticada em vários aspectos, principalmente na política. Conforme Pezat (2006), a absorção do positivismo pela sociedade gaúcha, entre as décadas finais do século XIX e as iniciais do século XX, é um dos traços mais característicos da história e da cultura do Rio Grande do Sul, inclusive na conjuntura política e no projeto de poder praticado pelo Partido Republicano Rio-grandense no Rio Grande do Sul da Primeira República (PEZAT, 2006).

Conforme Oliven (1989, on-line), o estado do Rio Grande do Sul repetidamente é contraposto "como um todo ao resto do País, com o qual manteria uma relação especial, a ponto de ser às vezes chamado jocosamente por outros brasileiros de "este país vizinho e amigo do Sul'". Historicamente, a tensão entre autonomia e integração é um tema recorrente na relação do Rio Grande do Sul com o resto do Brasil (OLIVEN, 1989). Isto pode ser visto no cenário dos esportes náuticos.

\section{Representações regionalistas nas entidades náuticas}

A idealização da Federação Rio-Grandense de Remo iniciou entre os membros do Grêmio de Natação e Regatas Almirante Tamandaré (GRAT), mas os primeiros passos na direção da instauração de uma nova entidade dirigente partiram dos organizadores do Comitê de Regatas. Esta entidade somente poderia ser presidida por sócios dos clubes fundadores, todavia, para a organização do Wanderpreiss de 1907, o presidente convocou uma comissão com representantes dos clubes existentes na capital sul-rio-grandense (LICHT, s/d). Desta forma, emergia a necessidade de reformulação do órgão responsável pela organização do remo no estado.

Outro fator motivador de uma transformação nesta direção foi a instalação do Conselho Superior de Regatas no Rio de Janeiro. A União de Regatas Fluminense foi idealizada em 1895, mas oficialmente instalada em 1897 e modificada para Conselho Superior de Regatas em 1900 (CONFEDERAÇÃO BRASILEIRA DE REMO, 2015). De acordo com Cancella (2011, p. 5), essa alteração advém da tentativa de "dominar as sociedades de regatas, controlando a organização do remo nacional, mas este objetivo recebeu muita resistência de entidades que regulamentavam o esporte em outras regiões do país". No entanto, sua denominação foi alterada novamente em 1902 para Federação Brasileira das Sociedades de Remo, quando começou a organizar os campeonatos brasileiros de remo, o que reforçou a perspectiva unificadora do remo nacional almejado pela instituição carioca (REEBERG, 2007).

Quando decidiu assumir esse papel, de entidade federativa brasileira do remo, nos seus códigos publicou que tinha como objetivos representar o esporte náutico brasileiro, defender seus interesses e promover seu engrandecimento. Ainda, sugere o abarcamento do código a todos os clubes de regatas existentes no país, desde que suas propostas fossem integralmente aceitas. Contudo, esta tentativa de conquistar um capital simbólico para esta instauração se deparou com resistências de outras instituições regulamentadoras do esporte no país. Foi o caso, por exemplo, do Comitê de Regatas, que não aceitou ter um conselho regulamentador. Assim, a "tentativa de unificação do controle do remo não teve o sucesso esperado pelos idealizadores" (CANCELLA, 2011).

De acordo com Bourdieu (2001), o poder simbólico é um modo pelo qual as classes dominantes (ou campos dominantes) são beneficiárias de um capital simbólico, disseminado e reproduzido por meio de instituições e práticas sociais, que lhes possibilita exercer o poder. De tal modo que a Federação Brasileira de Sociedades de Regatas foi buscar relações com a Fédération Internationale des Sociétés d'Aviron (FISA) e, em 1903, esta entidade, em uma estratégia de domínio do campo esportivo em questão, passa a ser reconhecida pela entidade federativa mundial como a representante oficial do remo brasileiro. Apesar de ter no seu qua- 
dro de clubes associados principalmente clubes do Rio de Janeiro, esta federação conseguiu dar os primeiros passos para tornar-se a atual Confederação Brasileira de Remo. Assim, a vinculação da Federação com a FISA, como símbolo, tornou possível o consenso acerca do sentido do mundo social, o qual contribui fundamentalmente para a reprodução da ordem social dominante.

A única referência a alguma influência do Conselho Superior de Regatas nos clubes sul-rio-grandenses foi encontrada nos estatutos do Club Italiano Canottieri Duca degli Abruzzi (CICDA), que determina que seus barcos devessem estar de acordo com as normas do Conselho Superior de Regatas (A FEDERAÇÃO, 8/2/1909). Ressalta-se que o CICDA ainda utilizou a denominação antiga, mesmo esta não sendo mais empregada após sete anos, talvez, pela resistência em aceitar a nova entidade. Outra evidência de tal situação é a primeira referência à Federação Brasileira de Remo, que foi encontrada no jornal A Federação do dia 13 de junho de 1918, relatando uma regata entre brasileiros e portugueses (A FEDERAÇÃO, 13/06/1918).

Segundo o site da Confederação Brasileira de Remo (2015), a unificação entre as entidades estaduais aconteceu apenas em 1916, com a fundação da Confederação Brasileira de Desportos (CBD). Juntamente com o remo e a natação, esta instituição passou a coordenar a maioria dos esportes praticados no Brasil. A nova entidade extraiu da Federação Brasileira de Sociedades de Remo a organização do campeonato brasileiro, a partir de 1919, o que restringiu sua atuação ao Rio de Janeiro.

Provavelmente, diante do estabelecimento da entidade dirigente, os sul-rio-grandenses se viram obrigados a construir uma nova representatividade para os esportes náuticos no estado. Tal movimento iniciou-se com a instalação da Comissão Superior de Regatas para a organização do Wanderpreiss de 1907, quando os membros do GRAT convidaram representantes dos clubes existentes na cidade para uma reunião nas suas dependências. Na reunião estavam presentes os clubes: Ruder Club Porto Alegre (RCPA), Ruder Verein Germania (RVG), Grêmio de Regatas Almirante Tamandaré (GRAT), Club Italiano Canottieri Duca degli Abruzzi (CICDA) e Grêmio Náutico Rio-grandense (GNR).

A exposição da ideia de modificação da identidade do Comitê de Regatas para Federação Rio-grandense de Remo e o registro de fundação aconteceram durante as comemorações do dia 7 de Setembro, Dia da Independência do Brasil, quando estavam presentes autoridades, dentre elas, o presidente do RCPA, indicado a assumir a presidência da entidade (A FEDERAÇÃO, 08/09/1908). Neste mesmo dia, o tenente Ildefonso Pinto ${ }^{2}$, orador militar, fez um discurso, que foi publicado pelo jornal A Federação, dias mais tarde (A FEDERAÇÃO, 18/9/1908).

O orador inicia o texto elencando os barcos que desfilavam pelas águas do Guahyba, desde os de trabalho e lazer até os gigs esportivos, com destaque para a velocidade dos barcos esportivos (A FEDERAÇÃO, 18/9/1908, p. 1). Em seguida, demonstra o viés positivista de sua formação ao conectar os tipos de barcos existentes à lei dos três estados do francês Auguste Comte. ${ }^{3}$ "Chaminés, mastros, remos, caldeiras, velas forquetas, indicam os trez estados de evolução - força muscular, vento e vapor - que se succederam na predominância e ainda coexistem" (A FEDERAÇÃO, 18/9/1908, p. 1).

\footnotetext{
${ }^{2}$ Em Porto Alegre, há a Rua Dr. Ildefonso Pinto, no Bairro Santa Teresa, assim como, também, a Escola Estadual Ildefonso Pinto, localizada na Rua João S. do Amaral, 236, no Centro, e a Estação de Trem com o mesmo nome, demolida em 1972 (CHAVES, 20/05/2015; MACHADO, 2010).

${ }^{3}$ Auguste Comte foi o criador da doutrina positivista, a qual surgiu na França no século XIX e era, primeiramente, um pensamento filosófico e social que valorizava a humanidade. "Em um segundo momento, após o encontro do mentor da doutrina com sua musa inspiradora Clotilde de Vaux, Comte reformulou o pensamento trazendo aspectos religiosos à doutrina que se tornou a chamada 'Religião da Humanidade"' (NEVADO, 2008, p. 6).
} 


\section{Os esportes náuticos e o positivismo sul-rio-grandense}

No Rio Grande do Sul, o positivismo foi incorporado profundamente na política e na arquitetura, ainda hoje é possível identificar prédios e esculturas inspirados em seus ideais. A lei dos três estados de Auguste Comte se refere aos três estados teóricos diferentes e irredutíveis: o teológico, o metafísico e o positivo. No teológico, o homem perscruta os seres nas suas causas e interpreta-os sobrenaturalmente. No metafísico, os agentes sobrenaturais são substituídos por entidades abstratas que são a razão de todos os fenômenos. No positivo, o espírito humano renuncia ao conhecimento absoluto para se entregar pelo raciocínio e pela observação às leis invariáveis de sucessão e semelhança (NEVADO, 2008).

Na sua explanação sobre a lei dos três estados, ao referir-se à passagem do estado teológico para o metafísico, Comte afirma ainda que, do mesmo modo que a teologia, a metafísica busca acima de tudo explicar a natureza íntima dos seres, a origem e o destino de todas as coisas, o modo essencial de produção de todos os fenômenos (COMTE, 1947). Nesse momento, já não domina a pura imaginação, no entanto, não se trata ainda da verdadeira observação. Auguste Comte substitui Deus pelo Grande Ser, que aparece como a personificação da ordem social e da própria sociedade. O autor francês sistematiza aquela evolução intersecular com a lei dos três estados, na busca de superar as teorias morais anteriores - a teológica e a metafísica:

o espírito humano, dada a sua natureza emprega sucessivamente, em cada uma das suas pesquisas 3 métodos de filosofar, de caracteres essencialmente diferentes e mesmo radicalmente opostos: primeiro o método teológico, depois o método metafísico e por fim o método positivo. Donde decorre a existência de 3 tipos de filosofia ou de sistemas gerais de concepções sobre o conjunto dos fenómenos, que mutuamente se excluem: a primeira é o ponto de partida necessário da inteligência humana; a terceira, o seu estado fixo e definitivo; a segunda destina-se unicamente a servir de transição (COMTE, 1947, p. 30 ).

Na interpretação de Ildefonso Pinto, o vento configura-se no estado teológico ou fictício, o ponto de partida necessário da inteligência humana; o vapor, o estado metafísico, ou abstrato, destina-se unicamente a servir de transição; e a força muscular era o conhecimento científico ou positivo, o seu estado fixo e definitivo da evolução. Desta maneira, caracteriza a prática de esportes, no caso o remo, como o estado positivo, que a doutrina positivista, seguida por muitos sul-rio-grandenses e vista como verdade, determinava como o estado de perfeição do conhecimento, certificado pela evidência que provém da demonstração. Este dado revela o imaginário predominante em torno dos esportes naquele período, pois expressa a interpretação do pensamento dominante em relação à prática do remo, provavelmente, um dos fatores que contribuiu para a disseminação dos clubes esportivos náuticos no Rio Grande do Sul.

Tal conjuntura ganhou força com inserção do GRAT e seus idealizadores, oficiais de alta patente da Marinha brasileira, formados na Escola Militar da Praia Vermelha no Rio de Janeiro, considerados os oficiais "científicos". Segundo Góis Júnior (2003), ser positivista no período era, sobretudo, acreditar na ciência, ser um cientificista. Juntamente com esses militares, estava o médico Ricardo Machado, também adepto do ideário positivista (WEBER, 1999). De acordo com Góis Júnior (2003), a Educação Física e os esportes no Brasil ganham espaço graças a esta abordagem científica, "concebe-se a ideia de que a Educação Física, co- 
mo prática defendida pelos militares, logicamente, teria uma tradição positivista desde o século XIX” (GÓIS JÚNIOR, 2003, s/p).

Após essa explanação positivista, Ildefonso Pinto relaciona o movimento do remo em escaleres com o alívio sentido pelos passageiros dos barcos que se utilizam das hélices, como o primeiro sinal que a chegada ao destino está próxima: "A pancada subtil do remo soa melhor, então, para quem só tem ouvido o rumor da hélice" (A FEDERAÇÃO, 18/9/1908, p. 1). Em seguida, lembra que o mesmo movimento era exercido pelos trabalhadores da pesca, que movimentavam o trapiche perto do Mercado Público Municipal, onde os peixes eram vendidos. " [...] é elle [o remo] que dá o pão aos filhos de muitos pobres" (A FEDERAÇÃO, 18/9/1908). Ainda, que remar é uma importante ferramenta dos tripulantes dos barcos em caso de naufrágio. Após, refere ao remo nos clubes, como esporte e lazer "nos clubs de regatas o remo serve ao mesmo tempo de diversão e de exercício muscular" (A FEDERAÇÃO, 18/9/1908, p. 1). Assim, organizou em uma ordem linear uma espécie de historiografia da prática, que inicia de uma forma utilitária, ganhando representações de lazer e chegando ao esporte institucionalizado.

O longo discurso se encaminha para felicitar o GRAT pelo aniversário de fundação, "que seus barquinhos delgados, ligeiros, sejam e victorias alcancem, nos pareos que correrem" (A FEDERAÇÃO, 18/9/1908, p. 1), para, em seguida, instaurar a fundação da federação de remo. "Ella promoverá a união dos remadores, dará mais disciplina e espírito de unidade as regatas, fará muito pelo desenvolvimento do sport" (A FEDERAÇÃO, 18/9/1908, p. 1).

Destaca-se a ênfase dada à questão de que a entidade irá promover a união, reforçada no parágrafo seguinte: "que todos os sócios do remo tenham o sentimento de pertencerem a uma unidade maior, e o espírito de corporação há de penetrai-os" (A FEDERAÇÃO, 18/9/1908, p. 1). Tal fragmento do texto demonstra, mais uma vez, a tendência positivista. A linha de pensamento da doutrina positivista era sintetizada em sete palavras: real, útil, certo, preciso, relativo, orgânico e simpático, elaborada em um sistema de valores adaptado à realidade vivida na época da Revolução Industrial, que destacasse o ser humano, a paz e a concórdia universal. A crença da ciência como a verdade se estabeleceu ainda mais nos clubes de esportes náuticos, com o advento do ano de 1909. Dois clubes instauram as salas de ginástica para os remadores e nadadores, no GRAT e no CICDA (LICHT,s/d; LICHT, s/d), inspirados no exemplo dado pelos esportistas de Harvard.

Percebe-se, também, que o orador realça um novo momento no cenário dos clubes esportivos náuticos, possivelmente, em razão das modificações advindas com a transformação da entidade organizacional, na qual o idioma da comunicação interna foi modificado para o português brasileiro, e a diretoria passa a aceitar membros que não fossem teuto-brasileiros, representação reforçada pela escolha da data de instauração, o Dia da Independência do Brasil. Embora a mudança fizesse a entidade desenvolver uma identificação mais próxima de uma brasilidade, o fator imigração europeia ainda era muito forte em Porto Alegre, pois, quando da realização da primeira regata, foi anunciada a morte do rei da Inglaterra, Eduardo VII, o que levou os organizadores a transferir a data da competição (A FEDERAÇÃO, 7/5/1910).

O primeiro campeonato de Porto Alegre ocorreu no dia 15 de maio de 1910. O anuncio foi feito juntamente com uma lista dos clubes federados. Ressalta-se que, dentre estes, estavam apenas clubes porto-alegrenses, RCPA, RVG, GRAT, Club de Regatas Almirante Barroso (CRAB), GNR, CICDA, embora a denominação da entidade fosse uma afirmação da abrangência de todo o Rio Grande do Sul e existissem clubes de esportes náuticos em Rio Grande e em Pelotas (A FEDERAÇÃO, 14/5/1910). Um dos páreos foi especialmente batizado de Federação Brasileira das Sociedades de Remo, com destaque para o comentário: "Homenagem á co-irmã do Rio de Janeiro" (A FEDERAÇÃO, 14/5/1910, p. 1). Ao mesmo tempo 
em que faz o tributo, ressalta que são coirmãs, ou seja, estão em nível de igualdade hierárquica.

A organização da regata foi cuidadosamente preparada, inclusive com as orientações sobre a raia, que "foi construída por profissionaes, de conformidade com o que preceituam os artigos do código da federação" (A FEDERAÇÃO, 14/5/1910, p. 1). Além disso, a nota jornalística avisa sobre o policiamento embarcadiço da região e demonstra o apoio da autoridade responsável: "embarcações estranhas ás regatas e ao serviço de policiamento, deverão conservar-se fora dos limites de raia, sob pena de incorrerem nas multas a que estão sujeitos pela capitania do porto" (A FEDERAÇÃO, 14/05/1910, p. 1).

Indícios extraídos da nota jornalística sobre como se desenvolveu a competição demonstram como as regatas atraíam os porto-alegrenses: "a concorrencia foi extraordinária, principalmente de exmas. famílias" (A FEDERAÇÃO, 16/5/1910, p. 4). Da mesma forma mostra que a preferência dos espectadores era pelo GRAT: "notava-se logo que a corrente de sympathias era para a galharda tripulação do 'gig' < Tijuca $>$, do <Grêmio Tamandaré $>$ [...]. Estrondosa aclamação, que attingiu o auge, coroou a nova surpreendente vitória do glorioso <grêmio Tamandaré>" (A FEDERAÇÃO, 16/5/1910, p. 4).

O sucesso da inauguração foi bastante comentado pelos jornais locais, no entanto, o evento seguinte da FRGR foi o ponto de partida para transformações da conjuntura destes esportes, como distanciamento e inserção de clubes, remodelação da entidade organizacional e o surgimento de uma nova prática esportiva.

\section{Conclusão}

O cenário dos clubes náuticos no Rio Grande do Sul reflete o quanto o estado era composto por contatos culturais, apesar de alguns grupos presentes na sociedade sul-riograndense ainda não tivessem se mobilizado para a instauração de clubes no período estudado, como os africanos, que apenas em 1949 inauguraram a sua primeira associação. Embora considerado um estado com origem populacional essencialmente europeia, ainda assim havia a predominância biológica e cultural de uma específica categoria de mestiçagem, entre portugueses, espanhóis e índios. Estas culturas eram combinadas na construção sul-riograndense.

Com esta variedade de representações clubísticas, o Comitê de Regatas começa a sofrer modificações, que se consolidaram quando este se transformou em Federação Riograndense de Remo (FRR). Essa entidade regional resistiu aos tentames da Federação Brasileira das Sociedades de Remo, idealizada no Rio de Janeiro, que desejava o domínio organizacional das práticas esportivas náuticas no território brasileiro. Porém, os sul-rio-grandenses mantiveram a tradição de resistência às ordens originárias da capital do país no período e não aceitaram a superioridade deste órgão, apesar de seu reconhecimento pela FISA, de representatividade nacional.

A nova federação subestimou a paixão dos torcedores por seus clubes, que, por um conflito de representações identitárias, conhecido como Conflito do Trapiche Preto, fez com que essa entidade se dissolvesse e surgisse a Liga Náutica Riograndense (LNRG). Devido aos acontecimentos do Conflito do Trapiche Preto, o GRAT foi excluído das atividades iniciais da LNRG, o que obrigou o clube a buscar alternativas para a sua sobrevivência.

Neste novo momento, o GRAT assumiu as festividades comemorativas do feriado de Nossa Senhora dos Navegantes, que o fez ganhar destaque nos jornais e na sociedade sul-riograndense. As várias atividades do GRAT, assim como as conexões externas dos seus associados, renderam ao clube o convite para ser personagem da primeira participação de um clube sul-rio-grandense em uma regata internacional, realizada em Montevidéu, no Uruguai, 
quando as culturas de diversos países da América Latina se encontraram. A estratégia deu certo, tais atividades o trouxeram de volta à LNRG.

Provavelmente, o destaque do GRAT, juntamente com os acontecimentos da Primeira Guerra Mundial - que enfraqueceram os clubes teuto-brasileiros - e a representatividade nacional do patrono sul-rio-grandense contribuíram para que outras associações esportivas náuticas e aquáticas fossem fundadas com a mesma denominação, Almirante Tamandaré, em diversas cidades do estado, como Jaguarão, Pelotas e Uruguaiana.

Os clubes eram ambientes de lazer e socialização. Todavia, como os seus frequentadores estavam vinculados a uma elite socioeconômica, estes também tinham figuras com capital político, principalmente ligados ao Partido Republicano Riograndense (PRR), que seguia a doutrina positivista de Auguste Comte, bastante disseminada no estado. Possivelmente, esta era uma das razões da difusão das práticas esportivas, que encontravam no discurso cientifico a justificativa para essas atividades. Ser positivista neste período era, sobretudo, acreditar na ciência, ser um cientificista, um dos alicerces dos discursos esportivos. Estes deslizavam entre características higienista e positivistas.

\title{
SPORTS NAUTICAL, CULTURAL IDENTITIES AND POSITIVISM IN RIO GRANDE DO SUL
}

\begin{abstract}
This study aims to investigate how the nautical sports clubs assimilated representations from Rio Grande do Sul in the early twentieth century. The nautical sports clubs in Rio Grande do Sul (RS) were established by European immigrants. New identities were composed from the cultural contact that occurred among immigrants. In this context, the Rio Grande do Sul identities of the clubs were built up with new representations in the sports scene. The documentary corpus consisted of printed sources, drawn from official documents of the clubs and newspapers that circulated by the state. Analysis of the sources occurred through software ATLAS.ti 7.5.6. Through the interpretation of the scenario of nautical sports clubs in RS, you can see that the state was culturally heterogeneous.
\end{abstract}

Keywords: History of Sport. Rowing. Clubs. Identities.

\section{DEPORTES NÁUTICOS, IDENTIDADES CULTURALES Y EL POSITIVISMO EN RIO GRANDE DO SUL}

\section{Resumen}

Este estudio tiene el objetivo de investigar cómo los clubes deportivos náuticos se incorporaron a las representaciones de Rio Grande do Sul (RS) a principios del siglo XX. Los clubes deportivos náuticos de la ciudad fueron establecidos por los inmigrantes europeos y, por el contacto cultural, nuevas identidades fueron compuestas. Las identidades del Rio Grande do Sul de los clubes fueron construidos con nuevas representaciones en el escenario deportivo. El corpus documental consistió en fuentes impresas, a partir de documentos oficiales de los clubes y periódicos que circularon en la ciudad. El análisis de las fuentes se produjo a través del software ATLAS.ti 7.5.6. La interpretación de la escena de clubes deportivos náuticos de RS muestra que la ciudad era culturalmente heterogénea.

Palabras clave: História del Deporte. Remo. Clubes. Identidades. 


\section{Referências}

A FEDERAÇÃO. 7 de setembro. Porto Alegre, 18 set. 1908.

1909.

. Estatutos do club Italiano <Canottieri Ducca degli Abruzzi>. Porto Alegre, 8 fev.

. Matchs internacionais - Brazileiros versus portugueses. Porto Alegre, 13 jun. 1918.

Aviso. Porto Alegre, 07 maio 1910.

. Regatas - campeonato. Porto Alegre, 14 maio 1910.

. Secção sportiva - regatas. Porto Alegre, 16 maio 1910.

Também a associação Grêmio Tamandaré... Porto Alegre, 8 set.1908.

BOURDIEU, P. O poder simbólico. 4. ed. Rio de Janeiro: Bertrand Brasil, 2001.

BURKE, P. Hibridismo cultural, São Leopoldo, Editora Unisinos, 2003.

CANCELLA, K. O esporte e a Marinha do Brasil: primeiras aproximações e a institucionalização da prática esportiva através da criação da Liga de Sports da Marinha. In: SIMPÓSIO NACIONAL DE HISTÓRIA, 26, 2011. Anais.. São Paulo, jul. 2011.

CANCLINI, N. G. Narrar o multiculturalismo. In: Consumidores e cidadãos: conflitos multiculturais da globalização. 4 ed. Rio de Janeiro: UFRJ, 2001. p. 143-160.

Culturas híbridas: estratégias para entrar e sair da modernidade. 4. ed. São Paulo:

UNESP, 2011.

CHIZZOTTI, A. Pesquisa qualitativa em Ciências Humanas e Sociais: evolução e desafios. Revista Portuguesa de Educação, Universidade do Minho, Braga, Portugal, v. 16, n. 2, 2003.

CONFEDERAÇÃO BRASILEIRA DE REMO. Remo Brasil. [2015]. Disponível em: <http://www.remobrasil.com/institucional/historia> . Acesso em: 21 maio 2015.

COMTE, A. Discurso sobre o positivismo. Lisboa. Seara Nova, 1947.

DARBON, Sébastien. Diffusion des sports et impérialisme anglo-saxon. De l'histoire événementielle à l'anthropologie. Paris : Éditions de la Maison des Sciences de l'Homme, 2008.

GILZ, C. Os desafios e facilidades do uso do programa de Software atlas/ti na análise de dados da pesquisa: a coleção "Redescobrindo o universo religioso" na Formação do professor. In: CONGRESSO NACIONAL DE EDUCAÇÃO, 7 . Anais... Curitiba, Paraná, 2007. 
GÓIS, E.; LOVISOLO, H. Descontinuidades e continuidades do movimento higienista no Brasil do século XX. Revista Brasileira de Ciência do Esporte, Campinas, v. 25, n.1, 2003.

GOIS JUNIOR, E. Conhecimento positivista da Educação Física e esporte. In: DaCOSTA, L.P. Atlas do Esporte no Brasil. Rio de Janeiro, Shape, 2005. p. 717-718.

HALL, S. Da diáspora: identidades e mediações culturais. Belo Horizonte: UFMG, 2003.

IBGE. Instituto Brasileiro de Geografia e Estatística. Países - Brasil. 2016. Disponível em: <http://paises.ibge.gov.br/\#/pt/pais/brasil/info/sintese>. Acesso em: 18 ago. 2016.

LICHT, H. Ruder Club Porto Alegre, apostila, acervo pessoal, Porto Alegre, s/d.

LICHT, H. Grêmio de Regatas Almirante Tamandaré - Subsídios históricos, apostila, acervo pessoal, Porto Alegre, s/d.

LICHT, H. Club Italiano Canottieri Ducca degli Abruzzi - subsídios históricos, apostila, acervo pessoal, Porto Alegre, s/d.

MARRERO, A. R. História genética dos gaúchos: dinâmica populacional do Sul do Brasil. 2006. XX f. Tese (Doutorado) - Programa de Pós-Graduação em Genética e Biologia Molecular, Universidade Federal do Rio Grande do Sul, 2006.

MAZO, Janice Z. et al. Associações esportivas no Rio Grande do Sul: lugares e memórias. Novo Hamburgo/RS: FEEVALE, 2012. (Versão digital).

NEVADO, P. O enquadramento filosófico para a investigação: algumas reflexões introspectivas ao positivismo. ADVANCE - Centro de Investigação Avançada do ISEG, Lisboa, Working Paper, n. 4, 2008.

OLIVEN, R. O Rio Grande do Sul e o Brasil: uma relação controvertida. Revista Brasileira de Ciências Sociais, São Paulo, v. 3, p. 5-14, 1989.

O gaúcho brasileiro e o gaúcho platino, como vistos do Brasil. In: REUNIÓN DE ANTROPOLOGIA DEL MERCOSUR, 2 2017. Piriápolis. Anais... Piriápolis: RAM, 2017.

PETRI, V. A produção de efeitos de sentidos nas relações entre língua e sujeito, um estudos discursivo da dicionarização do "gaúcho". Letras, Santa Maria, v. 18, n. 2, 2008.

PEZAT, P. O positivismo na abordagem da recente historiografia gaúcha. Anos 90, Porto Alegre, v. 13, n. 23-24, jan./dez. 2006.

QUEIRÓS, C. A. Questão social no Rio Grande do Sul: positivismo, borgismo e a incorporação do proletariado à sociedade moderna. Antíteses, Londrina, v. 1, n. 1, jan./jun. 2008.

RAMIL, V. A estética do frio. Pelotas: Satolep Livros, Pelotas, 2009.

REEBERG, W. História da Confederação Brasileira de Remo: das raízes à fundação. 2007. Disponível em: <http://www.cbrremo.com.br/files/a cbr.asp?acbr key=1 >. Acesso em: 21 maio 2015. 
REVERBEL, C. O gaúcho. Porto Alegre: L\&PM, 2002.

SILVA, C. F. O remo e a história de Porto Alegre: mosaico de identidades culturais. 2011. Dissertação (Mestrado) - Programa de Pós-Graduação em Ciências do Movimento Humano, Escola de Educação Física, Universidade Federal do Rio Grande do Sul, Porto Alegre, 2011.

SILVA, C. F. Esportes náuticos e aquáticos no Rio Grande do Sul, Brasil: esportivização e contatos culturais nos clubes. 2015. Tese (Doutorado) - Programa de Pós-Graduação em Ciências do Movimento Humano da Escola de Educação Física da Universidade Federal do Rio Grande do Sul, 2015.

WEBER, B. T. Positivismo e ciência médica no Rio Grande do Sul: a Faculdade de Medicina de Porto Alegre. História Ciência e Saúde, Manguinhos, v. 5, n. 3, nov. 1998/ fev. 1999.

Recebido em: 28/09/2016

Revisado em: 16/02/2017

Aprovado em: 29/08/2017

Endereço para correspondência:

carol_ed.fis@hotmail.com

Carolina Fernandes da Silva

Universidade Federal de Viçosa

Avenida Peter Henry Rolfs, s/n

36570-900 -Viçosa - MG 